\title{
Analysis of Coupling Rurality Index and Rural Transformation Development of Jiangxi Province
}

\author{
Zhi-juan Wang, Xiao-bo Shu, Ming-juan Li \\ College of Geography and Environment, Jiangxi Normal University, Nanchang, China
}

\section{Email address:}

Wangzhijuan93@163.com(Zhi-juan Wang)

\section{To cite this article:}

Zhi-juan Wang, Xiao-bo Shu, Ming-juan Li. Analysis of Coupling Rurality Index and Rural Transformation Development of Jiangxi Province. Science Innovation. Vol. 6, No. 1, 2018, pp. 4-9. doi: 10.11648/j.si.20180601.12

Received: December 19, 2017; Accepted: January 11, 2018; Published: March 9, 2018

\begin{abstract}
This paper takes 78 counties (cities) in Jiangxi Province as the research object, evaluating the coupling rurality index and rural transformation development of Jiangxi Province in 2005 and 2014. The result shows that, in 2014, the rurality index is significantly lower than in 2005; the deviation degree of rural transformation was decreased.as the same time; there is a negative correlation between the main control factors and the polar diameters of rurality index and rural transformation development.
\end{abstract}

Keyword: Rurality Index, Rural Transformation Development, Coupling Mechanism, Jiangxi Province

\section{江西省乡村性与乡村转型发展耦合关系研究}

\section{汪志娟, 舒晓波, 李明娟}

地理与环境学院, 江西师范大学, 南昌, 中国

\section{邮箱}

Wangzhijuan93@163.com（汪志娟）

摘要: 本文以江西省78个县 (市) 为研究对象, 对2005年和2014年江西省乡村性水平进行评价, 利用力学平衡模型判 别2005年和2014年江西乡村转型发展偏离度，最后探讨乡村性与乡村转型发展之间的耦合关系。结论显示: 2014年乡 村性水平较2005年有明显下降; 2014年较2005年乡村转型发展的偏离程度有所减小; 乡村性与乡村转型发展各主控因 子以及极径之间有存在负相关关系。

关键词: 乡村性, 乡村转型发展, 耦合关系, 江西省

\section{1. 引言}

乡村是城市以外自然环境资源广衰、以农业生产为主、 经济发展水平相对于城市较落后的广阔区域。目前乡村发 展处于转型的重要时期, 城市化带来的农村人口向城市迁 移、农村地区转变为城市地区以及生活方式的城市化对乡 村人口、劳动力和非农经济活动影响显著。原有的城市用 地不足以承载巨大的人口规模从而推动城市土地向外扩
张, 原有的农村土地转为城市用地 $[1]$ 。一些发达国家早在 20 世纪 80 年代已开始转变城镇化的发展路径, 开始注重城 乡关系的重新调整, 注重乡村的发展 [2]。作为衡量乡村发 展转型是否可持续发展的重要标准一人口、土地和产业 在城乡之间配置的协调性 [3,4], 已成为学术界研究的重点。 乡村问题解决的前提条件是掌握乡村发展的状态和规律, 对乡村有整体的、全面的认知。本文通过对江西省乡村性 以及乡村转型发展的研究, 对掌握乡村发展的状态和规律 具有重要意义。 


\section{2. 研究区域与研究方法}

\section{1. 研究区域与数据来源}

江西省位于中国东南部, 整个地貌以山地、丘陵为主, 北部为鄱阳湖平原, 四周多山脉。本文在剔除市区基础上, 共包括78个县域研究区。

土地数据以1995年、2005年、2014年江西省遥感影像 解译数据和国土部门提供的2006-2020年土地利用总体规 划数据为基础; 县域社会经济数据以《中国县域社会经济 统计年鉴》、《中国区域经济统计年鉴》、《新中国五十 年的江西》（1949-1998）、《新中国六十年的江西》

（1949-2009）、江西省11个地级市统计年鉴以及江西省 各县统计公报数据为数据源, 选取1995年、2005年、2014
年江西省县域相关统计数据, 个别年份缺失的数据采用相 邻年份差值法、面积平均加权法、以及利用年均増长率获 得。

\section{2. 研究方法}

\subsection{1. 乡村性判断}

乡村性是对乡村地域的综合表现, 其概念内涵随着乡 村发展演变而不断丰富和拓展[5,6,7]。本文参考周华、龙 花楼、刘彦随等 [8]研究成果, 结合江西省实际情况, 将乡 村性评价划分为人口发展、耕地发展和产业发展 3 个方面, 建立县域尺度乡村性指标体系（见表1）。其中各指标的 权重采用熵权法[9]获得, 通过各指标标准化后的结果加权 计算乡村性指数。

表1 江西省乡村性评价指标。

\begin{tabular}{|c|c|c|c|}
\hline 指标层 & 具体指标 & 内涵及计算方法 & 指标说明 \\
\hline 人口发展 & 乡村人口变化率 & $\begin{array}{l}\text { 反应城镇化过程中乡村人口变化状况, 乡村人口变化越大, 乡村性越强。通过计算末期 } \\
\text { 乡村人口数变化数与初期乡村人口数比值来表示 }\end{array}$ & + \\
\hline 耕地发展 & 耕地变化速率 & $\begin{array}{l}\text { 反应耕地变化状况, 耕地变化越大, 乡村性越强通过计算末期耕地面积变化量与初期耕 } \\
\text { 地面积比值来表示 }\end{array}$ & + \\
\hline \multirow{3}{*}{ 产业发展 } & 第一产业就业比重 & $\begin{array}{l}\text { 反应第一产业就业状况, 就业比重越高, 乡村性越强。根据农林牧渔从业人数与乡村从 } \\
\text { 业人数比值来表示。 }\end{array}$ & + \\
\hline & 农地产出率 & $\begin{array}{l}\text { 反应第一产业发展状况, 农地产出率越高, 乡村性越弱。根据农业总产值与耕地总面积 } \\
\text { 比值来表示。 }\end{array}$ & - \\
\hline & & $\begin{array}{l}\text { 反应第一产业产出效率, 农业劳动生产率越高, 乡村性越弱。用农林牧渔总产值于农林 } \\
\text { 牧渔从业人数比值来表示 }\end{array}$ & - \\
\hline
\end{tabular}

\subsection{2. 乡村转型发展判别}

（1）判别方法: 三农问题是目前社会聚焦的一个重 大问题，三农问题的中心是农民问题，而农民问题的核心 是土地问题[10]。基于以上认识, 相关学者认为乡村转型 发展就是劳动力与土地的有效配置问题[11]。农村人口、 耕地和农居点作为农村的三大要素, 其有效配置就是乡村 转型发展的映射。因此, 对乡村转型的发展方向判别是通 过以上三大要素之间的关系, 结合力学平衡模型的判别方 法进行判定。

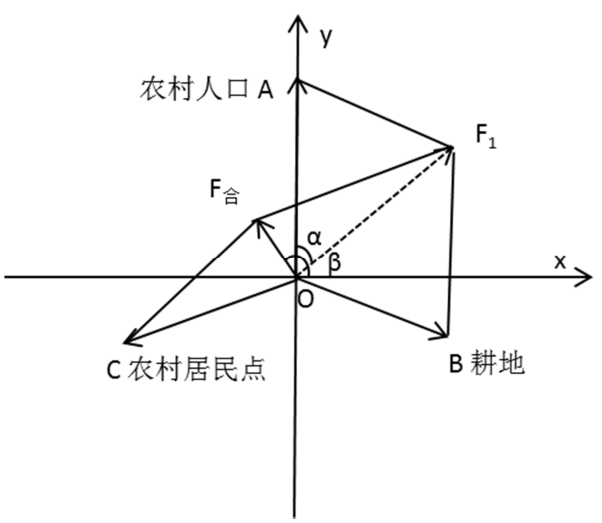

图1 乡村转型发展偏离度模型图。

图1中, 假设其他条件都为均质, 将以上三类资源要 素关系抽象为笛卡尔坐标系中的三个方向的作用力[4]。本

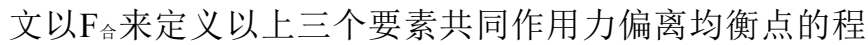
度, 用极径表示偏离距离, 用极角表示偏离方向, 表达式

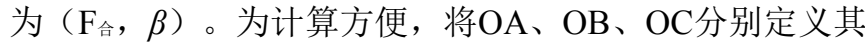
方向角度为 $\pi / 2,11 \pi / 6,7 \pi / 6$ 。 $\mathrm{OA} 、 \mathrm{OB} 、 \mathrm{OC}$ 分别用变化 度来表示:

$$
O A=\frac{U_{i}}{U_{S}} \quad O B=\frac{C_{i}}{C_{S}} \quad O C=\frac{H_{i}}{H_{S}}
$$

式中, $O A$ 为农村人口变化度, 用 $U C L$ 表示; $U_{i}$ 为 $i$ 研 究单元年均城市化率变化量; $U_{s}$ 为本文所研究时间段江西 省年均城市化率; $O B$ 为耕地变化度, 用 $C C L$ 表示; $C_{i}$ 为 $i$ 研究单元耕地年均变化量; $C_{s}$ 为各研究单元本文研究年份 耕地保有量到土地利用总体规划所确定的2020年任务量 年均变化量; $O C$ 为耕地变化度, 用 $R C L$ 表示; $H_{i}$ 为 $i$ 研究 单元年均农居点变化量; $H_{s}$ 为各研究单元本文研究年份农 居点面积到土地利用总体规划所确定的 2020 年农居点面 积年均变化量。

图 1 中, $\alpha$ 为 $\mathrm{F}_{1}$ 与 $\mathrm{OA}$ 的夹角, $\beta$ 为 $\mathrm{F}$ 合与 $\mathrm{X}$ 轴的夹 角, 为求 $\mathrm{F}$ 合和 $\beta$ 构建计算公式组如下:

$$
\begin{gathered}
F_{1}=\sqrt{O A^{2}+O B^{2}+a b s(2 O A \cdot O B) \cdot \cos (\angle X O A-(\operatorname{abs}(\angle X O B))} \\
\alpha=\arcsin \frac{a b s(O B) \cdot \sin (a b s(\angle X O B))}{F_{1}} \\
F_{\text {合 }} \sqrt{F_{1}^{2}+O C^{2}+a b s\left(2 F_{1} \cdot O C\right) \cdot \cos (a b s((\angle X O A-\alpha)-\angle X O C))} \\
\left.\angle F_{\text {合 }} O C=\arcsin \frac{F_{1} \cdot \sin (a b s((\angle X O A-\alpha)-\angle X O A))}{F_{\text {合 }}}\right) \\
\beta=\angle X O C-\angle F_{\text {合 }} O
\end{gathered}
$$


（2）象限划分： $O A 、 O B$ 和 $O C$ 指标均为矢量，分别 沿着 $\mathrm{OA} 、 \mathrm{OB}$ 和 $\mathrm{OC}$ 的反方向做延长线 $\mathrm{OA}^{\prime} 、 \mathrm{OB}^{\prime}$ 和 $\mathrm{OC}^{\prime}$ ，为 农村人口、耕地及农村居民点逆向变化矢量方向，则可将
结果空间划分为六个象限, 每个象限代表不同的乡村转型 发展特征，具体见表2。

表2 乡村转型发展偏离度动力状态划分及其特征。

\begin{tabular}{lllll}
\hline \multirow{2}{*}{ 象限 } & \multicolumn{2}{l}{ 矢量动力状态特征 } & \multicolumn{2}{l}{ 特征状态描述 } \\
\cline { 2 - 4 } & 农村人口 & 耕地 & 农村居民点 & \\
\hline I & - & + & - & 耕地和农村居民点协调转型, 耕地变化符合既定目标, 农村居民点逆向发展 \\
II & + & - & - & 农村人口和农村居民点协调转型, 城市化率变化符合既定目标, 农村居民点逆向发展 \\
III & + & - & - & 农村人口和耕地协调转型, 城市化率变化符合既定目标, 耕地逆向发展 \\
IV & - & - & + & 耕地和农村居民点协调转型, 农村居民点变化符合既定目标, 耕地逆向发展 \\
V & - & - & + & 农村人口和农村居民点协调转型, 农村居民点符合既定目标, 城市化率逆向发展 \\
VI & - & + & - & 耕地和农村人口协调转型, 耕地符合既定目标, 而城市化率逆向发展 \\
\hline
\end{tabular}

\subsection{3. 耦合关系判断}

Spearman秩相关系数是一个非参数性质 (与分布无关) 的秩统计参数, 其定义公式如下:

$$
\theta=\frac{\sum\left(R_{i}-\bar{R}\right)\left(S_{i}-\bar{S}\right)}{\sqrt{\sum\left(R_{i}-\bar{R}\right)^{2}\left(S_{i}-\bar{S}\right)^{2}}}
$$

式中 $\theta$ 为Spearman相关系数, $R_{i} 、 S_{i}$ 分别是两个相关性 分析变量第 $i$ 个值的秩, $\bar{R} 、 \bar{S}$ 分别是 $R_{i} 、 S_{i}$ 的平均值 [12]。 其取值区间为 $[-1,1]$, 当 $\theta>0$ 时，存在正相关，反之则 存在负相关。

\section{3. 计算结果分析}

\section{1. 乡村性评价指标结果分析}

根据表 1 的评价指标体系，对2005年和2014年78个研 究单元的乡村性进行评价, 分别以1995-2005年、2005-2014 年变化结果为乡村人口变化率和耕地变化速率计算依据, 以2005年、2014年相应的经济数据为第一产业就业比重、 农地产出率和农业劳动生产率计算依据。利用ArcGIS软件
中的自然断点法Natural Breaks (Jenks), 将2005年和2014 年江西省乡村性划分为弱乡村性、较弱乡村性、中等乡村 性、较强乡村性和强乡村性5个等级。由图2可知, 2005 年乡村人口变化率 0.1739 , 耕地变化速率 0.4511 , 第一产 业就业比重0.2060, 农地产出率0.1037, 农业劳动生产率 $0.0653 ; 2014$ 年乡村人口变化率 0.2577 , 耕地变化速率 0.1695 , 第一产业就业比重 0.3244 , 农地产出率 0.1662 , 农业劳动生产率 0.0822 。2005年江西省乡村性指数为 0.5427 , 到 2014 年乡村性指数为 0.4693 , 说明江西省乡村 得到了极大的发展, 城市化进程不断加快, 乡村性不断降 低。

赣北地区的乡村性总体低于赣南地区, 自赣南向赣北, 乡村性呈逐渐降低态势。说明乡村性受地级市的辐射影响 较大, 鄱阳湖生态经济区的建立也对其所属县（市）的发 展有交大的带动作用，乡村性水平较低。乡村性指数的高 值较多位于赣南山区县, 因赣南地区多位于山地丘陵区, 受地形因素的限制, 农业产出水平较低, 交通发展较为落 后, 城市化相对较慢, 因此, 赣南地区的乡村性保留地较 为完整、乡村性水平较高。



图2 江西省乡村性空间格局图。 


\section{2. 乡村转型均衡发展判别结果}

农村人口、耕地和农居点三个要素是否协调发展反映 着乡村转型发展的协调程度, 计算出2005年和2014年的农 村人口变化度 $(\mathrm{UCL})$ 、耕地变化度 $(\mathrm{CCL})$ 、农居点变 化度 (RCL) 三个要素。计算过程中, $\mathrm{U}_{\mathrm{i}}$ 为1995-2005年和 2005-2014年年均城市化率变化量, Us为1995-2005年和 2005-2014年江西省年均城市化率; $\mathrm{Ci}$ 为每个研究单元 1995-2005年和2005-2014年耕地年均变化量, 数据源于 1995年、2005年、2014年江西省遥感影像解译, Cs 为各研 究单元1995年、2014年耕地保有量到土地利用总体规划所 确定的2020年任务量年均变化量; Hi为每个研究单元 1995-2005年和2005-2014年农居点年均变化量, 数据同样 由1995年、2005年、2014年江西省遥感影像解译得到, Hs
分别为各研究单元 1995 年和 2005 年农居点面积到土地利 用总体规划所确定的 2020 年农居点面积年均变化量。三个 要素计算结果如图3所示。

图3显示，2005年至2014年，江西省大部分农村人口 变化度为正值, 符合农村发展的目标。农村人口变化速率 最快的县 (市) 在空间上呈现出了集聚的态势。耕地变化 度大于 0 的研究单元从 21 个增加至 54 个, 在空间上, 耕地 变化速率最快的地区主要分布于江西省北部的南昌市辖、 九江市辖、上饶市辖的县 (市), 上述县 (市) 的耕地占 用速率均高于土地利用总体规划所制定的目标值。农居点 变化度大于 0 的研究单元从 64 个减少至 49 个, 表明农居点 的扩张态势有所缓和。
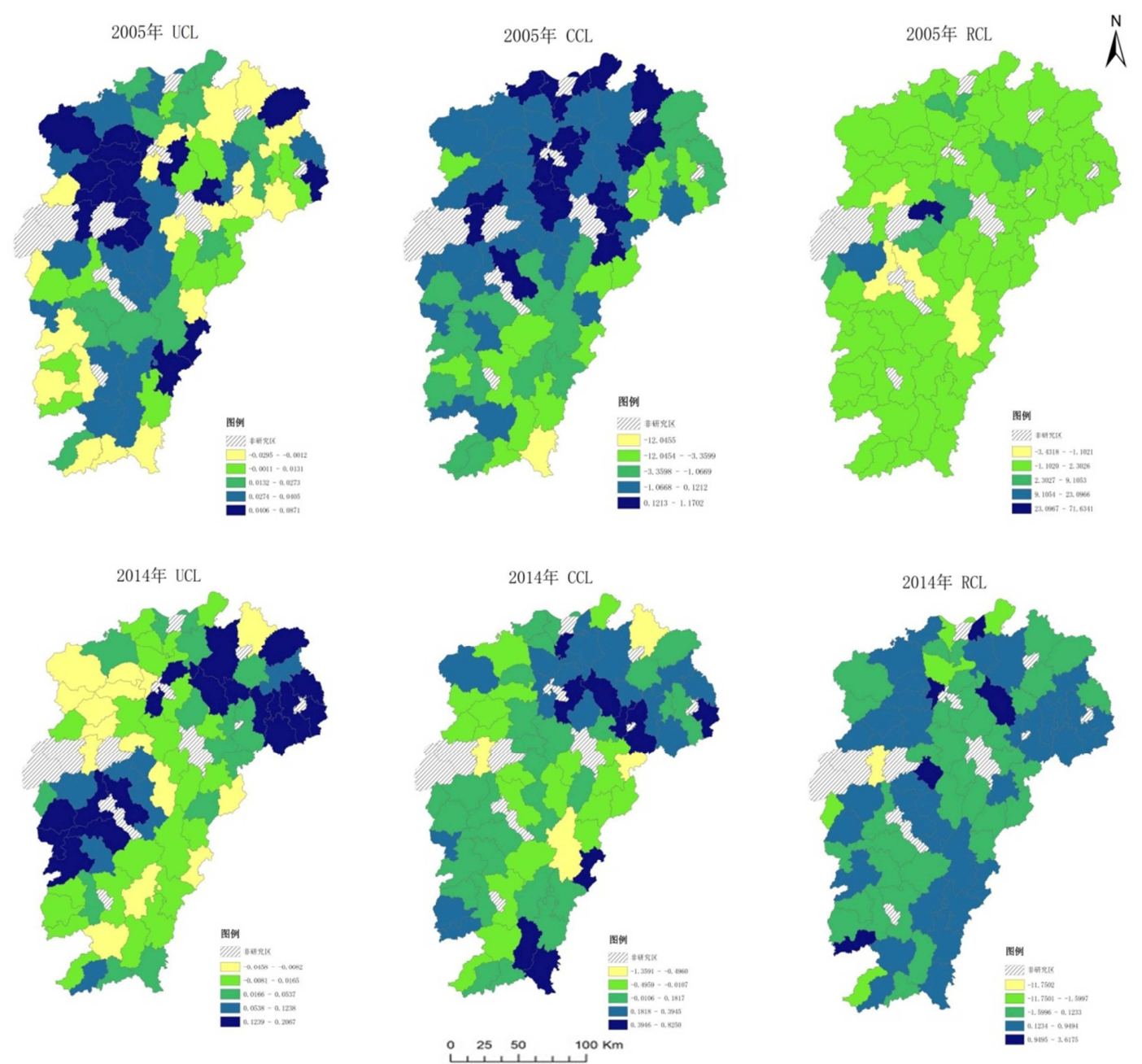

图3 西省农村人口变化度、耕地变化度、农居点变化度空间分异图。

本文利用极径值来定量化表征研究单元乡村转型发 展偏离程度，计算发现，极径值空间变化较大，并且各研 究单元在乡村转型发展过程中均有不同程度的偏离。2005 年江西省乡村转型发展的偏离程度普遍较大, 如图4所示, 极径值大于 1 的研究单元所占比例较大, 其中乡村转型发 展偏离程度最大的研究单元为樟树市、安福县和寻乌县。 相对于2005年, 2014年乡村转型发展整体有了向均衡发展
的态势, 从整体来看, 2014年乡村转型发展偏离程度明显 有所减小, 极径值较大的研究单元所占全省的比例显著下 降, 其中乡村转型发展偏离程度最大的研究单元为分宜县, 其余县 (市) 乡村转型发展偏离程度相对较小。说明从 2005 年至2014年以来, 乡村转型发展不断调整, 在农村人口、 耕地和农村居民点三个要素的发展中不断趋于均衡发展。 


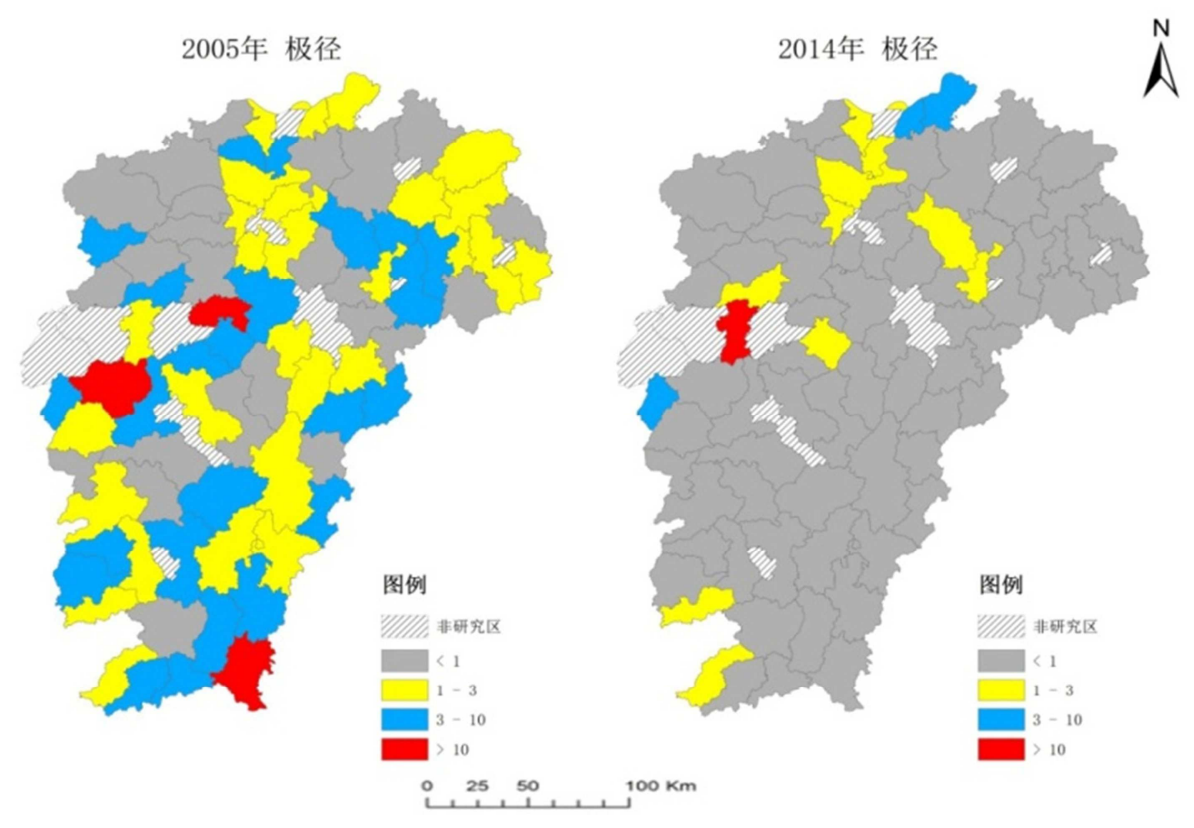

图4 江西省乡村转型均衡度极径空间分异图。
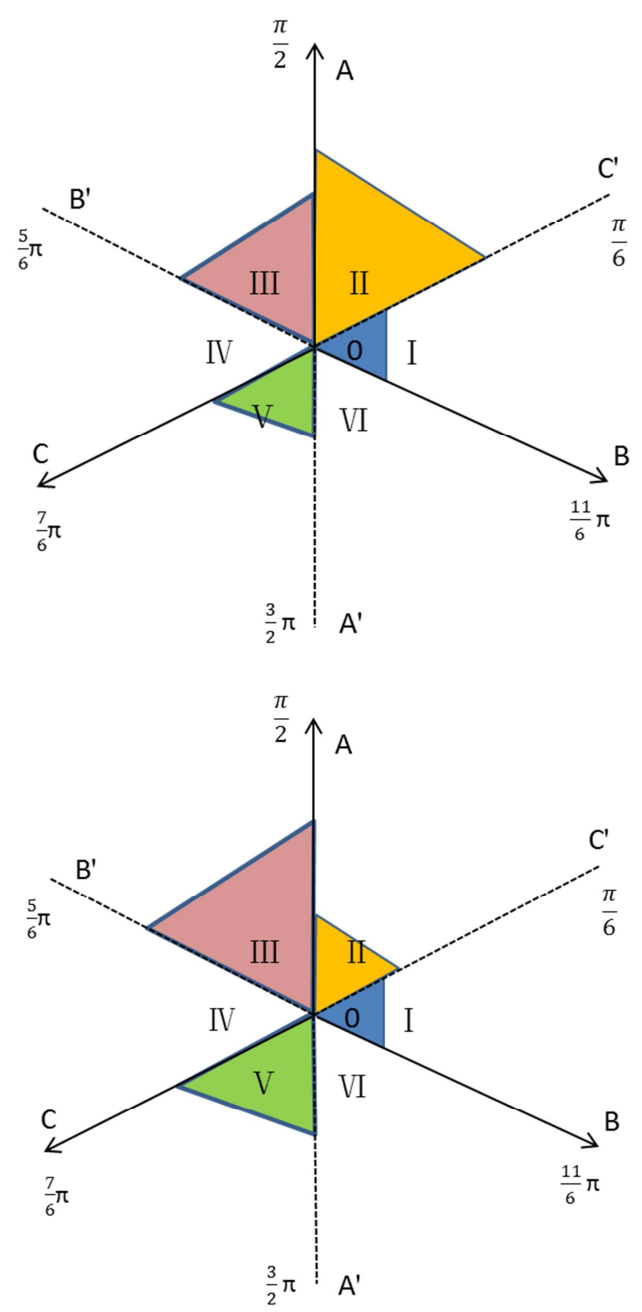

图5 江西省2005年 (上) 和2014年 (下) 研究单元象限分布图。
从图 5 可以看出, 2005 年极角分布的研究单元的数量 多少依次为象限 III $>$ 象限 V $>$ 象限 II $>$ 象限I，2014年极角分 布的研究单元的数量多少依次为象限 II $>$ 象限III $>$ 象限 V> 象限I。以上现象说明江西省乡村转型发展过程中, 2005 年乡村转型发展受困于耕地的县 (市) 所占比重最大, 而 2014年受困于农居点的县（市）所占比重最大。

\section{3. 乡村性与乡村转型发展耦合关系分析}

本文采用Spearman秩相关分析评价江西省乡村性与 乡村转型发展的耦合关系, 分析乡村性指数与乡村转型发 展的各个主控因子之间的相互关联程度具体计算结果见 表3和表4。

表3 2005年江西省乡村性与乡村转型偏离度及其各主控因子相关性。

\begin{tabular}{lllllll}
\hline & RI & UCL & CCL & RCL & 极径 & 极角 \\
\hline RI & 1 & $-.344^{* *}$ & $-.614^{* *}$ & $-.250^{*}$ & $-.547^{* *}$ & -.054 \\
UCL & $-.344^{* *}$ & 1 & $.229^{*}$ & .131 & -.041 & -.106 \\
CCL & $-.614^{* *}$ & $.229^{*}$ & 1 & $.270^{*}$ & $-.353^{* *}$ & .157 \\
RCL & $-.250^{*}$ & .131 & $.270^{*}$ & 1 & $.268^{*}$ & $.760^{* *}$ \\
极径 & $-547^{* *}$ & -.041 & $-.353^{* *}$ & $.268^{*}$ & 1 & $.347^{* *}$ \\
极角 & -.054 & -.106 & .157 & $.760^{* *}$ & $.347^{* *}$ & 1 \\
\hline
\end{tabular}

注: “*表示在置信度 (双测) 为 0.01 时, 显著相关; “表示在置信度 (双 测）为 0.05 时, 显著相关。

表4 2014年江西省乡村性与乡村转型偏离度及其各主控因子相关性。

\begin{tabular}{lllllll}
\hline & $\mathbf{R I}$ & $\mathbf{U C L}$ & $\mathbf{C C L}$ & $\mathbf{R C L}$ & 极径 & 极角 \\
\hline RI & 1 & $-.249^{*}$ & $-.508^{* *}$ & $-.625^{* *}$ & $-.513^{* *}$ & .015 \\
UCL & $-.249^{* *}$ & 1 & $.310^{* *}$ & .097 & .103 & -.044 \\
CCL & $-.508^{* *}$ & $.310^{* *}$ & 1 & $.226^{*}$ & $.471^{* *}$ & .094 \\
RCL & $-.625^{* *}$ & .097 & $.226^{*}$ & 1 & .146 & $.872^{* *}$ \\
极径 & $-.513^{* *}$ & .103 & $.471^{* *}$ & .146 & 1 & .149 \\
极角 & .015 & -.044 & .094 & $.872^{* *}$ & .149 & 1 \\
\hline
\end{tabular}

注: **表示在置信度 (双测) 为 0.01 时, 显著相关; *表示在置信度 (双 测）为 0.05 时，显著相关。 
结果表明乡村性RI与乡村转型发展各主控因子之间 有比较显著的相关性。2005年乡村转型发展各主控因子中, 乡村性RI与耕地变化度CCL的相关性最强, 这一结果表明, 建设用地占用耕地的面积越大, 乡村性水平越低; 农居点 扩张越大, 乡村性水平也越低。2014年乡村性RI与农居点 变化度RCL的相关性最强, 其次是耕地变化度CCL和农村 人口变化度UCL, 另外乡村性RI与极径也有较明显的相关 关系, 以上要素的值越大, 乡村性水平则越低。从上述结 果可以看出, 乡村转型发展过程中, 农村人口、耕地、农 居点以及转型偏离度均不同程度地影响着乡村性水平的 高低, 在不同的发展阶段, 各影响因素发挥的作用不尽相 同。

\section{4. 结论}

经研究表明, 2005 年江西省乡村性指数为 0.5427 , 2014年乡村性指数为 0.4693 , 社会经济经过近 10 年的发展, 江西省乡村得到了极大的发展, 城市化进程不断加快, 乡 村性水平不断降低; 另外地形对乡村性的保留也起了重要 作用, 赣北地区较赣南地区地势平坦, 农业产出水平高, 城市化进程快, 乡村地区受城市经济影响范围大, 乡村性 较弱。

江西省乡村转型发展受以上三种因素的共同作用影 响, 2005年受困于耕地因素影响的县 (市)所占比重最大, 而2014年受困于农居点因素影响的县 (市) 所占比重最大; 但随着乡村转型发展农村人口、耕地和农居点三个要素协 调程度趋于和缓。

通过秩相关分析结果表明, 乡村性与乡村转型发展各 主控因子之间存在负相关关系。农村人口、耕地、农居点 以及转型偏离度均不同程度地影响着乡村性水平的高低, 在不同的发展阶段, 各影响因素发挥的作用不尽相同。随 着各主控因子协调程度趋于和缓, 江西省乡村性水平不断 降低, 以上研究结果对把握江西省乡村发展状态和规律有 着重要意义。

\section{参考文献}

[1] 王桂新.城市化基本理论与中国城市化的问题及对策[J].人 口研究,2013,37(6):43-51。

[2] 何否.中国乡村一城镇转型的经济学分析[D].西北大学, 2011。

[3] 李婷婷,龙花楼.基于“人口一土地一产业”视角的乡村转型 发展研究——山东省为例 [J]. 经济地 理,2015,35(10):149-155。

[4] 周华,王炳君.江苏省乡村性及乡村转型发展耦合关系研究 [J].中国人口·资源与环境,2013,23(9):48-55。

[5] Cloke P. Conceptualizing rurality [M] // Cloke P, Marsden T, Mooney P H. Handbook of Rural Studies. London: Sage Publications, 2006: 18-28.

[6] 张小林.乡村概念辨析[J].地理学报.1998,53(4):79-85。

[7] 杨忍,刘彦随,龙花楼,等.中国乡村转型重构研究进展与展望 一逻辑主线与内容框架 [J]. 地理科学进 展, 2015,34(8):1019-1030。

[8] 龙花楼,刘彦随,邹健.中国东部沿海地区乡村发展类型及其 乡村性评价[J].地理学报,2009,64(4):426-434。

[9] 倪九派,李萍,魏朝富,等.基于AHP和熵权法赋权的区域土地 开发整理潜力评价[J].农业工程学报,2009,25(5):202-209。

[10] 范连生. 建国初期三农问题与乡村社会变迁 (1949-1956)——黔东南地区为个案的考察 [D].福建师范 大学,2009。

[11] 龙花楼. 论土地利用转型与乡村转型发展 [J]. 地理科学进 展,2012,31(2):131-138。

[12] 卢纹岱.SPSS for Windows统计分析-第2版[M].北京:电子工 业出版社,2002。 